\title{
Influence of Chromium Substitution on Structural, Electrical, and Magnetic Properties of $\mathrm{Ni}-\mathrm{Zn}-\mathrm{Cu}$ Ferrites
}

\author{
G. Satyanarayana ${ }^{a, b}$, G. Nageswara RaO ${ }^{b, *}$, K. Vijaya Babu ${ }^{a}$, \\ G.V. Santosh Kumar ${ }^{a}$ And G. Dinesh Reddy ${ }^{a}$ \\ ${ }^{a}$ Advanced Analytical Laboratory, Andhra University, Visakhapatnam-530 003, India \\ ${ }^{b}$ School of Chemistry, AU College of Science 83 Technology, Andhra University, \\ Visakhapatnam-530 003, India
}

Received: 5.10.2018 \& Accepted: 12.02.2019

Doi: 10.12693/APhysPolA.138.355

*e-mail: gollapallinr@yahoo.com

\begin{abstract}
In this work, $\mathrm{Ni}_{0.5} \mathrm{Zn}_{0.3} \mathrm{Cu}_{0.2} \mathrm{Fe}_{2-x} \mathrm{Cr}_{x} \mathrm{O}_{4}(x=0.02,0.04,0.06,0.08$, and 0.1$)$ ferrites are synthesized by sol-gel method, and study how relevant properties of the samples are modified accordingly. The structural, morphological, magnetic, and electrical features of the ferrites are evaluated by X-ray diffraction, scanning electron microscope, the Fourier transmission infrared spectra, vibrating sample magnetometer, electron spin resonance, and network analyser. The lattice constant decreases with chromium concentration and the decrease in lattice constant is attributed to the smaller ionic radius of chromium compared to iron. Distribution of metal cations in the spinel structure, estimated from X-ray diffraction data, show that along with $\mathrm{Ni}^{2+}$ ions, most of the $\mathrm{Zn}^{2+}$ and $\mathrm{Cu}^{2+}$ ions additionally occupy the octahedral B sites. The Fourier transform infrared spectra revealed two prominent frequency bands in the wave number range $400-600 \mathrm{~cm}^{-1}$ which confirm the cubic spinel structure. Magnetic properties, such as initial permeability, saturation magnetization, and coercivity have been investigated at room temperature. The frequency dependent dielectric constant is observed to decrease with the increased chromium concentration. This behaviour has been explained in accordance with the Koops phenomenological theory.
\end{abstract}

topics: $\mathrm{Ni}-\mathrm{Zn}-\mathrm{Cu}$ ferrite, cation distribution, XRD, magnetic properties, ESR

\section{Introduction}

Magnetic materials group consists of ferrite, which is a general term utilized for any ferrimagnetic ceramic material. Due to the intrinsic atomic level interaction between oxygen and metal ions, ferrite has higher resistivity of the order $10^{5}$ to $10^{7} \Omega \mathrm{cm}$ compared to ferromagnetic metals $[1-5]$. This enables the ferrite to invention applications at higher frequencies and makes it technologically very valuable. The main composition of iron oxide and metal oxides are ferrites. Among the different spinel ferrite material, nickel ferrites are of great importance due to their excellent chemical stability, high electrical resistivity, high coercivity, and moderate saturation magnetization [6-12]. They belong to an inverse structure category. The important magnetic properties originate mainly from the magnetic interaction between cations that are present in the tetrahedral A and the octahedral B site [13-15]. The nickel ferrite and substituted nickel ferrite have been studied by a number of researchers due to their vast applications. By substituting cations like copper ions, the properties of nickel zinc ferrite materials are further modified. The substitution of copper in nickel ferrite enhances the properties of nickel ferrite, which are useful in many device applications. $\mathrm{Ni}-\mathrm{Zn}-\mathrm{Cu}$ ferrites have emerged as important materials in recent years, owing to their potential applications in power transformers in electronics, antenna rods telecommunication, loading coils, and microwave devices. In the present paper, we report the structural, magnetic, electric, and dielectric properties of nickel-zinc--copper ferrite in order to study the effect of chromium in B site.

\section{Experimental}

The sol-gel method is used to synthesize $\mathrm{Ni}_{0.5} \mathrm{Zn}_{0.3} \mathrm{Cu}_{0.2} \mathrm{Fe}_{2-x} \mathrm{Cr}_{x} \mathrm{O}_{4}(x=0.02,0.04,0.06$, 0.08 , and 0.1 ) ferrites. AR chemicals such as nickel nitrate $\left(\mathrm{Ni}\left(\mathrm{NO}_{3}\right)_{2} \cdot 6 \mathrm{H}_{2} \mathrm{O}\right)$, zinc nitrate $\mathrm{Zn}\left(\mathrm{NO}_{3}\right)_{2}$. $3 \mathrm{H}_{2} \mathrm{O}$, copper nitrate $\left(\mathrm{Cu}\left(\mathrm{NO}_{3}\right)_{2} \cdot 6 \mathrm{H}_{2} \mathrm{O}\right)$, ferric nitrate $\left(\mathrm{Fe}\left(\mathrm{NO}_{3}\right)_{3} \cdot 9 \mathrm{H}_{2} \mathrm{O}\right)$, chromium nitrate $\left(\mathrm{Cr}\left(\mathrm{NO}_{3}\right)_{3} \cdot 9 \mathrm{H}_{2} \mathrm{O}\right)$, and citric acid $\left(\mathrm{C}_{6} \mathrm{H}_{8} \mathrm{O}_{7}\right)$ are used for the synthesis process. The molar metal nitrates to citric acid ratio are taken as 1:3. Ammonia solution is added to maintain the $\mathrm{pH}-7$. The collected compounds are then dried in oven for $2 \mathrm{~h}$. First pre-sintering of powder is carried out for $5 \mathrm{~h}$ at $1100^{\circ} \mathrm{C}$. The powder samples added with 
polyvinyl alcohol (PVA) as a binder are ground and then pressed at 5 tons $/ 5$ min pressure into a circular disk shaped pellet. For further investigations of electrical properties, the synthesized powder and pellet is sintered for $5 \mathrm{~h}$ at $1200^{\circ} \mathrm{C}$ and then used. The surface layers of the sintered pellet are carefully polished and washed in acetone, and then the pellet is coated with silver paste on the opposite faces which act as electrodes.

The synthesized $\mathrm{Ni}_{0.5} \mathrm{Zn}_{0.3} \mathrm{Cu}_{0.2} \mathrm{Fe}_{2-x} \mathrm{Cr}_{x} \mathrm{O}_{4}$ $(x=0.02,0.04,0.06,0.08$, and 0.1$)$ ferrites are characterized by standard techniques such as, $\mathrm{X}$-ray powder diffraction (XRD), scanning electron microscope (SEM), electron spin resonance (ESR), and network analyser. The XRD patterns are recorded at room temperature in the $2 \theta$ range of $10^{\circ}$ to $70^{\circ}$ using $\mathrm{CuK}_{\alpha}$ radiation $(\lambda=1.5405 \AA)$. The Fourier transform infrared (FTIR) spectra measurements are accomplished by Shimadzu IR-Prestige21 instrument in transmittance method with potassium bromide $(\mathrm{KBr})$ as IR window in the wave number region of 400 to $1300 \mathrm{~cm}^{-1}$. The particle morphology of the powders is observed using scanning electron microscopy images taken from JEOL JSM-6610L. The magnetic properties are measured using JEOL-JES-FA100 electron spin resonance (ESR) with X-band and Lake Shore 7400 vibrating sample magnetometer (VSM) at room temperature. The impedance study is performed by the Wayne-Kerr high frequency LCR meter Model 65120 in the frequency range $100 \mathrm{~Hz}$ to $120 \mathrm{MHz}$ at room temperature. Initial permeability is determined by 10 turns of SWG enameled copper wire on toroid's and inductance measurement is carried out at various frequencies using the Wayne-Kerr high frequency LCR meter Model 65120 in the frequency range $100 \mathrm{~Hz}$ to $120 \mathrm{MHz}$ at room temperature.

\section{Results and discussion}

\subsection{X-ray diffraction}

The indexed XRD patterns for all the samples corresponding to the as-burnt powder of $\mathrm{Ni}_{0.5} \mathrm{Zn}_{0.3} \mathrm{Cu}_{0.2} \mathrm{Fe}_{2-x} \mathrm{Cr}_{x} \mathrm{O}_{4}(x=0.02,0.04,0.06$, 0.08 , and 0.1 ) ferrites are shown in Fig. 1. It is indexed by different Bragg reflections that the strongest reflection comes from the (311) plane, which denotes the spinel phase. The pattern shows clearly pure cubic spinel ferrite phase with the reflections belonging to (220), (311), (222), (400), (422), (511), and (440). The analysis of the XRD pattern reveals the formation of single phase compounds. No extra peaks other than cobalt ferrite are present in the prepared samples. The XRD data of the present samples are used to determine the various structural parameters. From the X-ray peak broadening of the (311) peak, the crystallite size of synthesized ferrites is calculated using the Scherrer formula. It can be seen from Table I that the val-

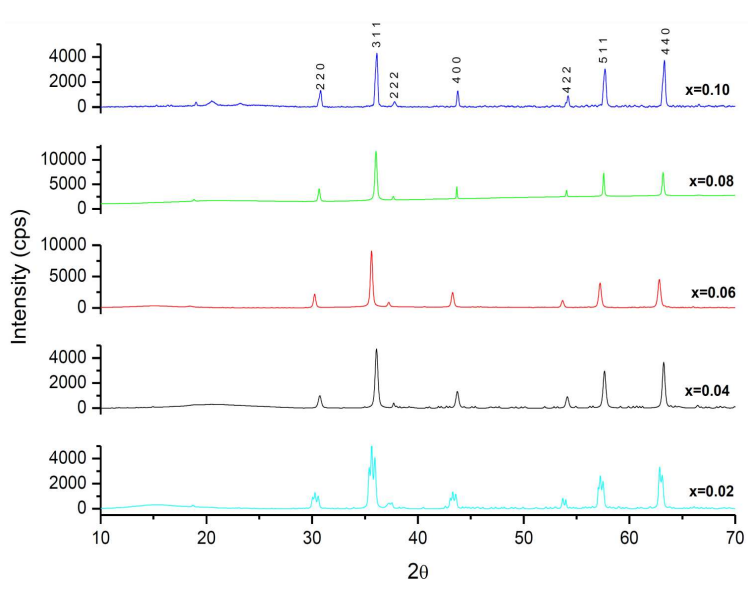

Fig. 1. X-ray diffraction patterns obtained for $\mathrm{Ni}_{0.5} \mathrm{Zn}_{0.3} \mathrm{Cu}_{0.2} \mathrm{Fe}_{2-x} \mathrm{Cr}_{x} \mathrm{O}_{4}(x=0.02,0.04,0.06$, 0.08 , and 0.1).

TABLE I

Lattice constant, cell volume, X-ray density, strain and crystallite size of $\mathrm{Ni}_{0.5} \mathrm{Zn}_{0.3} \mathrm{Cu}_{0.2} \mathrm{Fe}_{2-x} \mathrm{Cr}_{x} \mathrm{O}_{4}$ $(x=0.02,0.04,0.06,0.08$, and 0.1$)$ ferrites.

\begin{tabular}{c|c|c|c|c}
\hline \hline$x$-value & $\begin{array}{c}\text { Lattice } \\
\text { constant }[\AA]\end{array}$ & $\begin{array}{c}\text { Volume } \\
{\left[\AA^{3}\right]}\end{array}$ & $\begin{array}{c}\text { X-ray } \\
\text { density } \\
{\left[\mathrm{g} \mathrm{cm}^{-3}\right]}\end{array}$ & $\begin{array}{c}\text { Crystallite } \\
\text { size }[\mathrm{nm}]\end{array}$ \\
\hline 0.02 & 8.3572 & 583.6902 & 5.5047 & 5.623106 \\
0.04 & 8.3532 & 582.8525 & 5.4983 & 6.969928 \\
0.06 & 8.3031 & 572.4279 & 5.4726 & 7.315634 \\
0.08 & 8.2922 & 570.1765 & 5.3690 & 14.04266 \\
0.10 & 8.2861 & 568.9191 & 5.3689 & 9.292648
\end{tabular}

ues of the crystallite size vary in the range of 5.6 to $14.04 \mathrm{~nm}$. The particle size is not the same for all compositions, though all the samples are prepared under identical condition. The variation of crystallite size occurred due to preparation condition followed here, which gives rise to the different rate of ferrite formation for different concentrations of chromium.

The average value of the lattice parameter $(a)$, calculated from various Bragg's reflections observed in the XRD pattern of each samples are given in Table I. The lattice constant $a$ varies from $8.2861 \AA$ to $8.3572 \AA$. One can see that the increase of $a$ values goes linearly with the increase in chromium content from $x=0.02$ to 1.0 . This dependence is shown in Fig. 2. The lattice constant also depends upon the ionic radii of the dopant ions. A decrease in lattice constant is observed to increase in $\mathrm{Cr}^{3+}$ content in the synthesised ferrite system. The decrease in lattice constant is reasonably expected, and can be attributed to the substitution of smaller ionic radii of $\mathrm{Cr}^{3+}(0.64 \AA)$ ions as compared to that of larger $\mathrm{Fe}^{3+}(0.6 \AA)$ ions in the present ferrite system. It also causes an increase in the interatomic spacing parameter $d$ and consequently lattice parameter increases. The variation of lattice parameter with chromium content $x$ 
TABLE II

Hopping length $L_{\mathrm{A}}, L_{\mathrm{B}}$, tetrahedral bond $\left(d_{A L}\right)$, octahedral bond $\left(d_{B L}\right)$, tetra edge $\left(d_{A E}\right)$, and octahedral edge $\left(d_{B E}\right)$ (shared and unshared) of $\mathrm{Ni}_{0.5} \mathrm{Zn}_{0.3} \mathrm{Cu}_{0.2} \mathrm{Fe}_{2-x} \mathrm{Cr}_{x} \mathrm{O}_{4}(x=0.02,0.04,0.06,0.08$, and 0.1) ferrites.

\begin{tabular}{c|c|c|c|c|c|c|c}
\hline \hline$x$-value & $L_{\mathrm{A}}[\AA]$ & $L_{\mathrm{B}}[\AA]$ & $d_{A L}$ & $d_{B L}$ & $d_{A E}$ & $d_{B E}$ & $d_{B E U}$ \\
\hline 0.02 & 3.5911 & 2.9547 & 2.0120 & 1.9792 & 3.2856 & 2.6237 & 2.9639 \\
0.04 & 3.6170 & 2.9533 & 2.0110 & 1.9782 & 3.2840 & 2.6225 & 2.9625 \\
0.06 & 3.5953 & 2.9355 & 1.9990 & 1.9664 & 3.2643 & 2.6068 & 2.9447 \\
0.08 & 3.5906 & 2.9317 & 1.9963 & 1.9638 & 3.2600 & 2.6033 & 2.9409 \\
0.10 & 3.5879 & 2.9295 & 1.9949 & 1.9623 & 3.2576 & 2.6014 & 2.9387
\end{tabular}

TABLE III

Cation distribution and intensity ratios of $\mathrm{Ni}_{0.5} \mathrm{Zn}_{0.3} \mathrm{Cu}_{0.2} \mathrm{Fe}_{2-x} \mathrm{Cr}_{x} \mathrm{O}_{4}(x=0.02,0.04,0.06,0.08$, and 0.1$)$ ferrites.

\begin{tabular}{c|c|c|c|c|c|c|c}
\hline \hline \multirow{2}{*}{$x$-value } & Cation distribution & \multicolumn{2}{|c|}{$I_{(220)} / I_{(400)}$} & \multicolumn{2}{c|}{$I_{(422)} / I_{(440)}$} & \multicolumn{2}{c}{$I_{(220)} / I_{(440)}$} \\
\cline { 3 - 7 } & & Obs. & Cal. & Obs. & Cal. & Obs. & Cal. \\
\hline 0.02 & {$\left[\mathrm{Cu}_{0.2} \mathrm{Fe}_{0.8}\right]\left[\mathrm{Ni}_{0.5} \mathrm{Zn}_{0.3} \mathrm{Fe}_{1.08} \mathrm{Cr}_{0.02}\right] \mathrm{O}_{4}$} & 0.7474 & 0.7467 & 0.2589 & 0.2611 & 0.2849 & 0.2826 \\
0.04 & {$\left[\mathrm{Cu}_{0.2} \mathrm{Fe}_{0.8}\right]\left[\mathrm{Ni}_{0.5} \mathrm{Zn}_{0.3} \mathrm{Fe}_{1.06} \mathrm{Cr}_{0.04}\right] \mathrm{O}_{4}$} & 0.8892 & 0.8915 & 0.2509 & 0.2589 & 0.4843 & 0.4818 \\
0.06 & {$\left[\mathrm{Cu}_{0.2} \mathrm{Fe}_{0.8}\right]\left[\mathrm{Ni}_{0.5} \mathrm{Zn}_{0.3} \mathrm{Fe}_{1.04} \mathrm{Cr}_{0.06}\right] \mathrm{O}_{4}$} & 0.8228 & 1.1182 & 0.5028 & 0.4649 & 0.4634 & 0.5427 \\
0.08 & {$\left[\mathrm{Cu}_{0.2} \mathrm{Fe}_{0.8}\right]\left[\mathrm{Ni}_{0.5} \mathrm{Zn}_{0.3} \mathrm{Fe}_{1.02} \mathrm{Cr}_{0.08}\right] \mathrm{O}_{4}$} & 0.0212 & 0.0251 & 0.4147 & 0.5065 & 0.0138 & 0.0182 \\
0.10 & {$\left[\mathrm{Cu}_{0.2} \mathrm{Fe}_{0.8}\right]\left[\mathrm{Ni}_{0.5} \mathrm{Zn}_{0.3} \mathrm{Fe}_{1.00} \mathrm{Cr}_{0.1}\right] \mathrm{O}_{4}$} & 0.9335 & 0.9683 & 0.3339 & 0.3089 & 0.4789 & 0.4813
\end{tabular}

obeys the Vegard law. The value of lattice parameter for the present nickel ferrite sample is found to be $8.3259 \AA$ which is fairly agreed with the reported value. Similar type of variation in the lattice constant is observed for chromium substituted cobalt ferrite $[15,16]$.

The hopping length $\left(L_{\mathrm{A}}\right.$ and $\left.L_{\mathrm{B}}\right)$ between magnetic ions (the distance between the ions) in the tetrahedral A-site and the octahedral B-site can be calculated and the values of hopping lengths are listed in Table II. The variation of hopping length is decreased as chromium substitution shows similar behaviour as that of the lattice constant. The result is explained on the basis of variation of lattice constant with dopant concentration and Table II shows clearly the increase of $L_{\mathrm{A}}$ and $L_{\mathrm{B}}$ values.

\subsection{Theoretical lattice constant}

In order to verify the cation distribution, theoretical lattice parameter is calculated from the following relation, and compared with experimental values

$$
a_{t h}=\left(\frac{8}{3 \sqrt{3}}\right)\left(r_{\mathrm{A}}-r_{0}\right)+\sqrt{3}\left(r_{\mathrm{B}}+r_{0}\right),
$$

where $r_{\mathrm{A}}$ is tetrahedral site radius, $r_{\mathrm{B}}$ is the octahedral site radius, and $r_{0}$ is the radius of oxygen ion $(1.32 \AA)$. The ionic radius of the tetrahedral $\left(r_{\mathrm{A}}\right)$ and octahedral $\left(r_{\mathrm{B}}\right)$ sites are calculated by using the following relation:

$$
\begin{aligned}
& r_{\mathrm{A}}=\left[0.2\left(\mathrm{Cu}_{\mathrm{A}}^{2+}\right) r\left(\mathrm{Cu}_{\mathrm{A}}^{2+}\right)+0.8\left(\mathrm{Fe}_{\mathrm{A}}^{3+}\right) r\left(\mathrm{Fe}_{\mathrm{A}}^{3+}\right)\right], \\
& r_{\mathrm{B}}=\left[0.5\left(\mathrm{Ni}_{\mathrm{A}}^{2+}\right) r\left(\mathrm{Ni}_{\mathrm{A}}^{2+}\right)+0.3\left(\mathrm{Zn}_{\mathrm{B}}^{2+}\right) r\left(\mathrm{Zn}_{\mathrm{B}}^{2+}\right)\right. \\
& \left.\quad+x\left(\mathrm{Cr}_{\mathrm{B}}^{3+}\right) r\left(\mathrm{Cr}_{\mathrm{B}}^{3+}\right)+2-x\left(\mathrm{Fe}_{\mathrm{B}}^{3+}\right) r\left(\mathrm{Fe}_{\mathrm{B}}^{3+}\right)\right] / 2,
\end{aligned}
$$

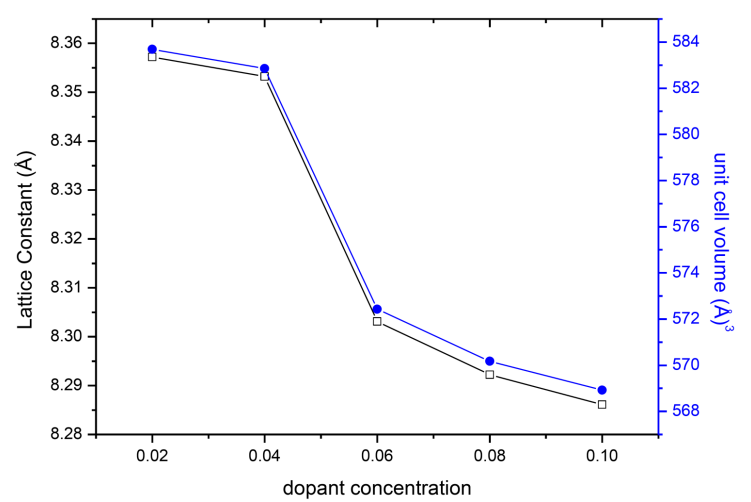

Fig. 2. Variation of lattice constant and unit cell volume with dopant concentration.

where $r_{\mathrm{Ni}^{2+}}, r_{\mathrm{Cu}^{2+}}, r_{\mathrm{Zn}^{2+}}, r_{\mathrm{Cr}^{3+}}$, and $r_{\mathrm{Fe}^{3+}}$ are the cationic radius of $\mathrm{Ni}, \mathrm{Cu}, \mathrm{Zn}, \mathrm{Cr}$, and $\mathrm{Fe}$ ions taken from the work of Shannon. In Table III one can see that the proposed cation distribution from $\mathrm{X}$-ray intensity calculations is in close agreement with the real distribution. When the chromium concentration increases, the $r_{\mathrm{A}}$ and $r_{\mathrm{B}}$ values decrease, as indicated in Table IV. The theoretical and experimental lattice parameter is maintaining the same decreasing trend. The difference, however, was found in the theoretical lattice constant values, that are slightly smaller than those of experimentally determined. This variation is due to the occupation of the chromium ions to the A-site by replacing iron ions in B-site [17].

The oxygen parameter ( $u$-value) is determined by using

$$
u=\left[\left(r_{A}+r_{0}\right) \frac{1}{\sqrt{3 a}}+\frac{1}{4}\right] .
$$


TABLE IV

Ionic radii of tetrahedral A-site $\left(r_{\mathrm{A}}\right)$, octahedral B-site $\left(r_{\mathrm{B}}\right)$, theoretical lattice constant $\left(a_{t h}\right)$ and oxygen positional parameter $(u)$ of $\mathrm{Ni}_{0.5} \mathrm{Zn}_{0.3} \mathrm{Cu}_{0.2} \mathrm{Fe}_{2-x} \mathrm{Cr}_{x} \mathrm{O}_{4} \quad(x=0.02,0.04,0.06$, 0.08 , and 0.1) ferrites.

\begin{tabular}{c|c|c|c|c}
\hline \hline$x$-value & $r_{\mathrm{A}}[\AA]$ & $r_{\mathrm{B}}[\AA]$ & $a_{t h}[\AA]$ & $u$-value $[\AA]$ \\
\hline 0.02 & 0.4593 & 0.7393 & 8.2310 & 0.3580 \\
0.04 & 0.4585 & 0.7383 & 8.2270 & 0.3579 \\
0.06 & 0.4476 & 0.7257 & 8.1769 & 0.3569 \\
0.08 & 0.4453 & 0.7230 & 8.1660 & 0.3566 \\
0.10 & 0.4439 & 0.7215 & 8.1599 & 0.3565
\end{tabular}

In spinel structure the oxygen positional parameter is of the order of $0.375 \AA$, therefore the arrangement of $\mathrm{O}^{2-}$ ions are equal exactly to a cubic closed packing. Although, in our case $u$-value is found to be $0.3580 \AA$. This value is smaller than the ideal value $(u=0.375 \AA)$, which may be due to the history of the samples, experimental or measurement errors. It also may be attributed to small displacement of anions from the ideal situation to form extended tetrahedral interstices $[18,19]$. Using the experimental values of oxygen positional parameter $u$ and lattice parameter $a$, the interionic distances, i.e., octahedral and tetrahedral bond length $d_{B L}$ and $d_{A L}$, tetrahedral edge, shared and unshared octahedral edge $\left(d_{A E}, d_{B E}\right.$ and $\left.d_{B E U}\right)$ are calculated, and the values are listed in Table IV. It is clear that the values of $d_{A E}, d_{A L}, d_{B E}, d_{B L}$, and $d_{B E U}$ decrease with increase in chromium concentration. This variation may be attributed to the substitution of cation and its distribution.

\subsection{Fourier transform infrared spectroscopy}

Figure 3 describes the FTIR spectra of $\mathrm{Ni}_{0.5} \mathrm{Zn}_{0.3} \mathrm{Cu}_{0.2} \mathrm{Fe}_{2-x} \mathrm{Cr}_{x} \mathrm{O}_{4}(x=0.02,0.04,0.06$, 0.08 , and 0.1 ) noted at room temperature at 350 $1300 \mathrm{~cm}^{-1}$ wave-number range. It can be observed from the FTIR spectra that the appearance of two persistent absorption bands corresponds to stretching vibration of octahedral complexes and tetrahedral at around $\approx 400$ and $\approx 600 \mathrm{~cm}^{-1}$ confirms the formation of spinel ferrite structure [20]. We observe that all samples exhibit two prominent absorption bands in the ranges $\approx 600 \mathrm{~cm}^{-1}\left(\nu_{1}\right)$ and $\approx 400 \mathrm{~cm}^{-1}\left(\nu_{2}\right)$. The band $\approx 400 \mathrm{~cm}^{-1}$ $\left(\nu_{2}\right)$ corresponds to the octahedral group complexes $\left(\mathrm{Fe}^{3+}-\mathrm{O}^{2-}\right)$, and the band $\approx 600 \mathrm{~cm}^{-1}\left(\nu_{1}\right)$ corresponds to stretching vibrations of the tetrahedral groups $\left(\mathrm{Fe}^{3+}-\mathrm{O}^{2-}\right)$. Table $\mathrm{V}$ presents different values of $\nu_{1}$ and $\nu_{2}$, and we notice that it varies slightly due to the difference in the $\mathrm{Fe}^{3+}-\mathrm{O}^{2-}$ distances for the octahedral and tetrahedral sites. In this present study, there are two major frequency bands: lower frequency band $\left(\nu_{2}\right)$ is observed at $400 \mathrm{~cm}^{-1}$ whereas the high frequency band $\left(\nu_{1}\right)$ is observed at $600 \mathrm{~cm}^{-1}$. The higher frequency band $\left(\nu_{1}\right)$ is nearly constant for all synthesized compounds. The low
TABLE V

FTIR transmittance bands obtained for $\mathrm{Ni}_{0.5} \mathrm{Zn}_{0.3} \mathrm{Cu}_{0.2} \mathrm{Fe}_{2-x} \mathrm{Cr}_{x} \mathrm{O}_{4} \quad(x=0.02,0.04,0.06$, 0.08 , and 0.1 ) ferrites.

\begin{tabular}{l|c|c|c|c}
\hline \hline$x$-value & $\nu_{1}$ & $\nu_{2}$ & $\begin{array}{c}K_{t} \times 10^{5} \\
{[\mathrm{dyn} / \mathrm{cm}]}\end{array}$ & $\begin{array}{c}K_{0} \times 10^{5} \\
{[\mathrm{dyn} / \mathrm{cm}]}\end{array}$ \\
\hline 0.02 & 667.39 & 419.50 & 1.664 & 1.458 \\
0.04 & 669.32 & 418.57 & 1.673 & 1.455 \\
0.06 & 667.39 & 419.53 & 1.662 & 1.477 \\
0.108 & 668.36 & 418.57 & 1.665 & 1.453 \\
0.10 & 667.39 & 418.57 & 1.659 & 1.454
\end{tabular}

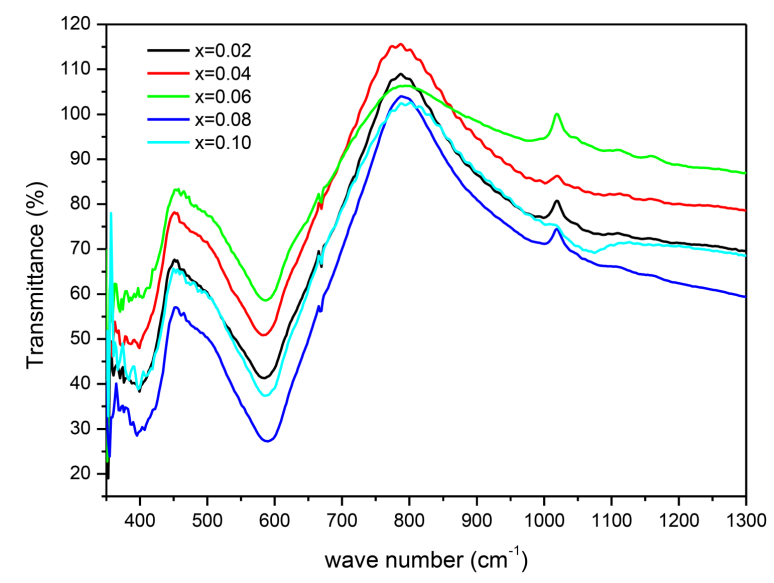

Fig. 3. FTIR spectra results obtained for $\mathrm{Ni}_{0.5} \mathrm{Zn}_{0.3} \mathrm{Cu}_{0.2} \mathrm{Fe}_{2-x} \mathrm{Cr}_{x} \mathrm{O}_{4} \quad(x=0.02,0.04$, $0.06,0.08$, and 0.1 ).

frequency band $\left(\nu_{2}\right)$ is slightly shifted to the higher frequency side, and broadening of the spectral band is also observed to increase in chromium concentration [21]. Due to its higher atomic weight and larger ionic radius than iron ions, which affects $\mathrm{Fe}^{3+}-\mathrm{O}^{2-}$ distances on B-sites, the broadening of the spectral band and shift in $\left(\nu_{2}\right)$ to higher frequency side is attributed to the occupancy of chromium ions on octahedral B-sites. Therefore, a slight shifting of $\nu_{2}$ bands towards low frequency is expected, because an increase in site radius reduces the fundamental frequency and therefore, the centre frequency of bands should shift to lower frequency side and vice versa $[22,23]$.

\subsection{SEM}

The scanning electron microscope (SEM) provides morphological pattern of the synthesized $\mathrm{Ni}_{0.5} \mathrm{Zn}_{0.3} \mathrm{Cu}_{0.2} \mathrm{Fe}_{2-x} \mathrm{Cr}_{x} \mathrm{O}_{4} \quad(x=0.02, \quad 0.04$, $0.06,0.08$, and 0.1$)$ ferrites samples presented in Fig. $4 \mathrm{a}-\mathrm{e}$.

It is very clear from SEM images of the ferrite system that the morphology of the particles is almost spherical in shape, but agglomerated to some extent, due to the interaction between magnetic particles. We also observe that uniform sized grains are 

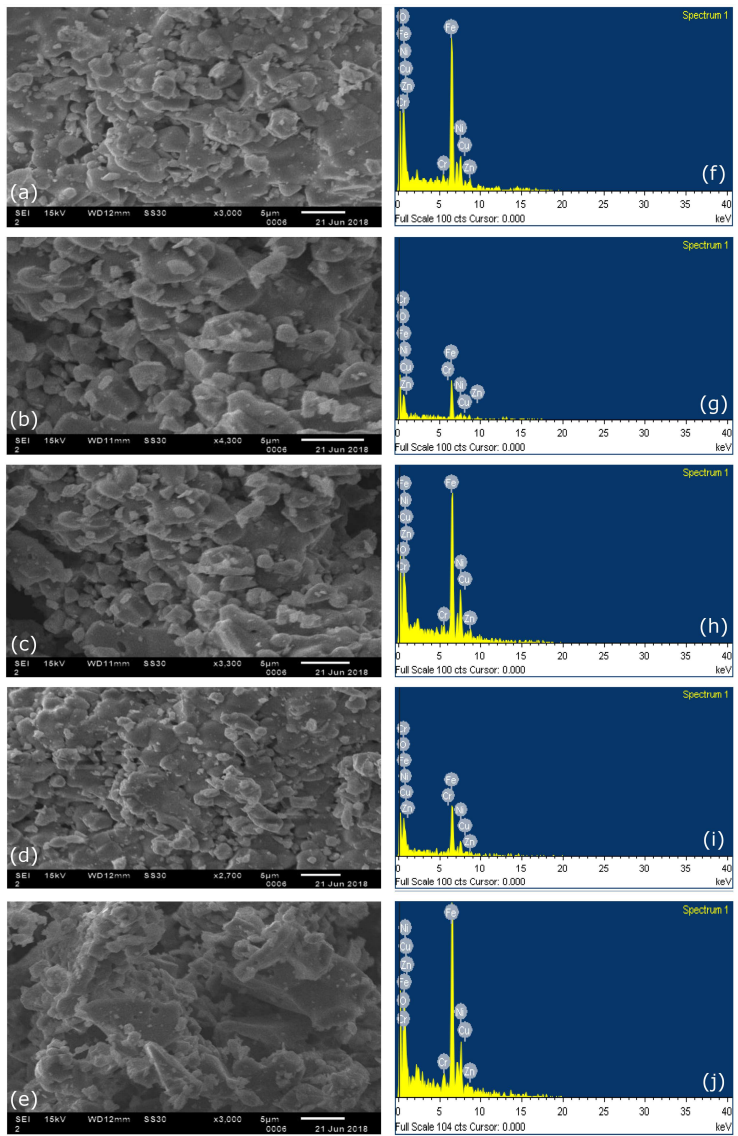

Fig. 4. SEM (a)-(e) and EDS (f)-(j) images of $\mathrm{Ni}_{0.5} \mathrm{Zn}_{0.3} \mathrm{Cu}_{0.2} \mathrm{Fe}_{2-x} \mathrm{Cr}_{x} \mathrm{O}_{4}(x=0.02,0.04,0.06$, 0.08 , and 0.1 , respectively).

distributed throughout the surface which exhibits decreasing trend together with chromium substitution. The particle size decreases significantly with increasing dopant concentration, since the ionic radius of chromium is smaller than that of iron. The clearness of SEM images of all our samples also reveals that there are no secondary phases. This phenomenon is supported by the absence of additional peaks in the XRD patterns. The micrograph of all the samples exhibits the presence of a number of smaller grains that are having large number of interfaces, which have a direct to the properties of these ferrites. These microstructure modifications may reflect the difference in the radii of the substitute cations $[24,25]$. The average grain size calculated from the instrument is found to be in the nanometre range of $10 \mathrm{~mm}$. The specific surface area is calculated by using the formula

$$
S=\frac{6000}{D \rho} \mathrm{m}^{2} / \mathrm{g},
$$

where $\rho$ is the density of the particles measured in $\mathrm{g} / \mathrm{cm}^{3}, D$ is the particle diameter in $\mathrm{mm}$. With the increase in dopant concentration, surface area decreases, and this indicates the nanocrystalline nature of the prepared samples. The decrease in grain size increases the surface area. As observed from the SEM images the porosity for all our samples is smaller. It is well known that the crystallite size and surface area play a significant role in the magnetic properties of ferrites due to the size of the magnetic domains.

The reliably quantitative composition analysis is done through energy dispersive spectroscopy (EDS) measurements. The values calculated in the present system indicate that the stoichiometry of the samples has almost been maintained after sintering process. The EDS spectra illustrated in Fig. $4 \mathrm{f}-\mathrm{j}$ show the presence of the elements $(\mathrm{Ni}, \mathrm{Zn}, \mathrm{Cu}, \mathrm{Cr}, \mathrm{Fe}$, and $\mathrm{O}$ ) without impurities. From these results, we confirm that the final composition of the samples is the same as that of starting composition without any extra impurity elements. The observed quantitative results indicate that the chromium concentration increases in the samples as expected based on synthesis method. The approximate compositions estimated from EDS data agree well with stoichiometric chemical compositions.

\subsection{Dielectric constant $\varepsilon_{r}$}

In Fig. 5, we have presented the variation in dielectric constant measured as a function of frequency for all synthesized ferrites under investigation at room temperature. It is observed from Fig. 5 that with increase in frequency, the dielectric constant decreases. There is no change in the behaviour of the dielectric constant for all different dopant concentrations, which is a normal dielectric behaviour of spinel ferrites. The decrease in dielectric constant with frequency is exponential in nature and analogous to the Maxwell-Wagner interfacial type polarization which is in agreement with the Koops phenomenological theory. The maximum dispersion of the dielectric constant is 0.08 , which is minimum for the sample. The maximum dispersion is attributed to the fact that available ferrous ions are higher than in other compositions. As a consequence, it is possible for these ions to be polarized to the maximum possible extent. The dielectric constant decreased with the frequency of the externally applied field increases gradually $(100 \mathrm{~Hz}$ to $120 \mathrm{MHz}$ ). This is because of the fact that, beyond a certain frequency of the externally applied electric field, the electronic exchange between ferrous and ferric ions cannot follow the alternating field

$$
\mathrm{Fe}^{2+} \leftrightarrow \mathrm{Fe}^{3+} .
$$

The other fact is that the electron exchange between $\mathrm{Fe}^{2+}$ and $\mathrm{Fe}^{3+}$ in an $n$-type semiconducting ferrites, and the whole exchange between $\mathrm{Ni}^{3+}$ and $\mathrm{Ni}^{2+}$ ions in $p$-type semiconductor ferrites cannot follow the frequency of the applied alternating field beyond a critical value of the frequency [26-29].

\subsection{Dielectric loss tangent $(\tan \delta)$}

The variation of dielectric loss tangent $(\tan \delta)$, as a function of frequency of the synthesized $\mathrm{Ni}_{0.5} \mathrm{Zn}_{0.3} \mathrm{Cu}_{0.2} \mathrm{Fe}_{2-x} \mathrm{Cr}_{x} \mathrm{O}_{4}(x=0.02,0.04,0.06$, 


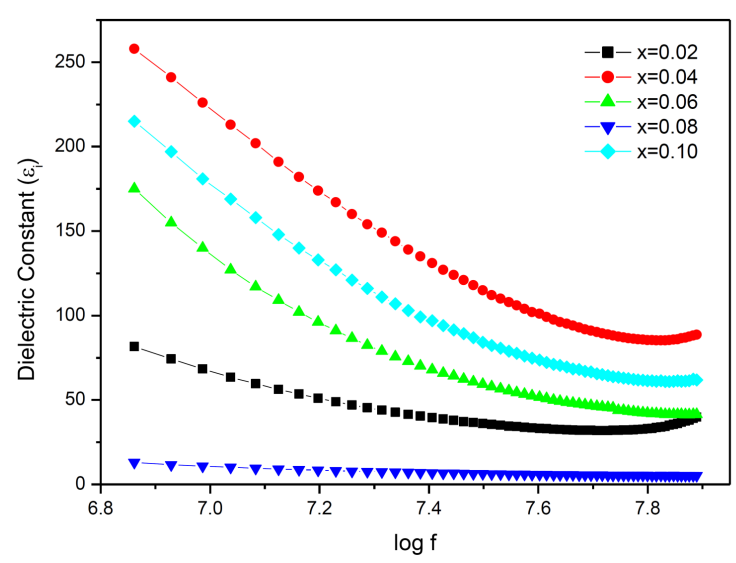

Fig. 5. Variation of dielectric constant with frequency of $\mathrm{Ni}_{0.5} \mathrm{Zn}_{0.3} \mathrm{Cu}_{0.2} \mathrm{Fe}_{2-x} \mathrm{Cr}_{x} \mathrm{O}_{4} \quad(x=0.02$, $0.04,0.06,0.08$, and 0.1 ).

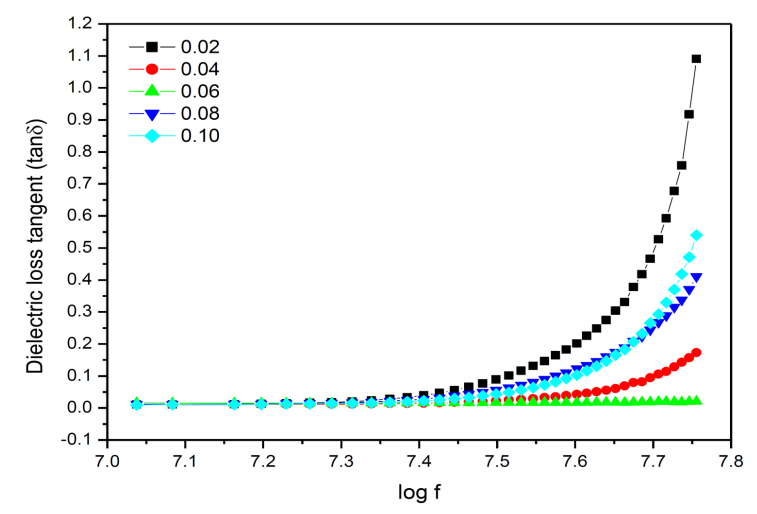

Fig. 6. Variation of dielectric loss tangent with frequency of $\mathrm{Ni}_{0.5} \mathrm{Zn}_{0.3} \mathrm{Cu}_{0.2} \mathrm{Fe}_{2-x} \mathrm{Cr}_{x} \mathrm{O}_{4} \quad(x=0.02$, $0.04,0.06,0.08$, and 0.10$)$.

0.08, and 0.10), is presented in Fig. 6, and an increasing trend with increasing frequency shows loss in the dielectric. The values of $\tan (\delta)$ depend on a number of factors such as a structural homogeneity and carrier concentration. The dielectric loss tangent increases exponentially with an increase in frequency. On the basis of the Maxwell-Wagner interfacial polarization, the observed behaviour of dielectric loss tangent can be explained. The compositional dependence of dielectric loss tangent increases with chromium concentration. The properties of spinel ferrites, that are of prime concern to users or designers, are mainly dielectric properties, such as dielectric tangent loss factor and dielectric constant. This can be attributed to the decreases in resistivity which causes reduction in dielectric loss tangent $[30,31]$.

\subsection{DC resistivity $(\rho)$}

Figure 7 shows the variation of DC resistivity with frequency for the synthesized ferrites. It is found that with increase in the frequency, the resistivity also increases.

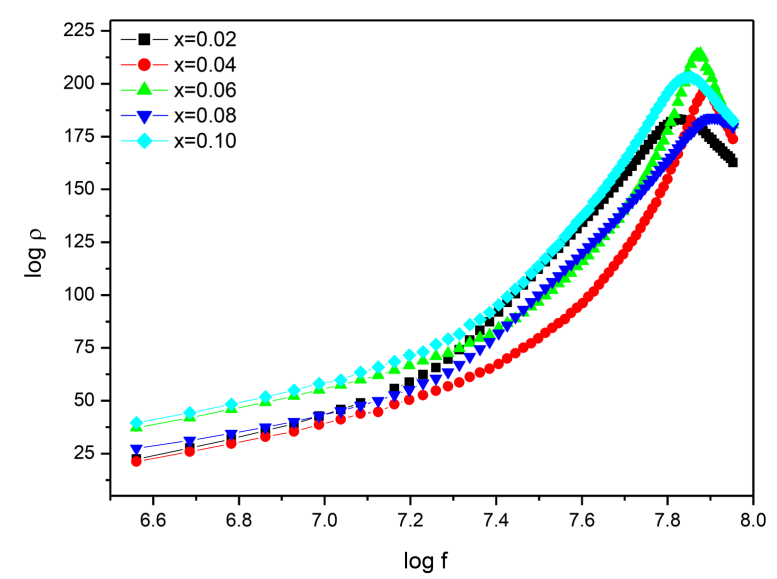

Fig. 7. Variation of $\log (\rho)$ with frequency of $\mathrm{Ni}_{0.5} \mathrm{Zn}_{0.3} \mathrm{Cu}_{0.2} \mathrm{Fe}_{2-x} \mathrm{Cr}_{x} \mathrm{O}_{4}(x=0.02,0.04,0.06$, 0.08 , and 0.10$)$ ferrites.

In case of ferrites, it is well known that electrons hop between $\mathrm{Fe}^{2+}$ and $\mathrm{Fe}^{3+}$, and holes hop between $\mathrm{Ni}^{3+}$ to $\mathrm{Ni}^{2+}$ in B-sites. Attributing to the fact that the ionic radius of $\mathrm{Cr}^{3+}(0.64 \AA)$ ions is smaller than that of $\mathrm{Fe}^{3+}(0.67 \AA)$ ions in the present ferrite system, during chromium substitution in iron, a part of chromium or iron will occupy the tetrahedral sites, by displacing the octahedral sites, and this leads to decrease in resistivity. This increase in the $\mathrm{Fe}^{3+}$ or $\mathrm{Cr}^{3+}$ ions in octahedral sites will increase the number of $\mathrm{Fe}^{2+}, \mathrm{Fe}^{3+}$ or $\mathrm{Cr}^{2+}$ or $\mathrm{Cr}^{3+}$ pairs octahedral sites, which increases the conductivity of ferrites. Therefore the resistivity is decreased by the addition of chromium. The decrease of resistivity might also be related to the decrease of porosity since the pores are non-conductive, which increases resistivity of the material. The resistivity decreases with the porosity because the charge carriers on their way face pores [32].

\subsection{Magnetic properties}

The magnetic properties play an important role in the applications of soft magnetic materials. At room temperature, the magnetic properties of the synthesized ferrite samples of $\mathrm{Ni}_{0.5} \mathrm{Zn}_{0.3} \mathrm{Cu}_{0.2} \mathrm{Fe}_{2-x} \mathrm{Cr}_{x} \mathrm{O}_{4}(x=0.02,0.04,0.06$, 0.08 , and 0.10 ) are studied by using hysteresis loop. The variation of saturation magnetization with applied field is shown in Fig. 8 for all compositions. As a normal behaviour, the magnetization increases with increase in applied magnetic field, and reaches to its saturation value at high fields. It is observed that saturation magnetization increases with increase in cobalt concentration. The increase in saturation magnetization is related to $\mathrm{A}-\mathrm{B}$ interaction. In the present case, $\mathrm{Fe}^{3+}$ ions having magnetic moment $5.92 \mu_{\mathrm{B}}$ are replaced by $\mathrm{Cr}^{3+}$ ions of $3.87 \mu_{\mathrm{B}}$. By using vibrating sample magnetometer, the saturation magnetization $\left(M_{s}\right)$ and magnetic moment $\left(n_{B}\right)$ is determined. At room temperature, the values of saturation magnetization and magnetic moment are obtained. 


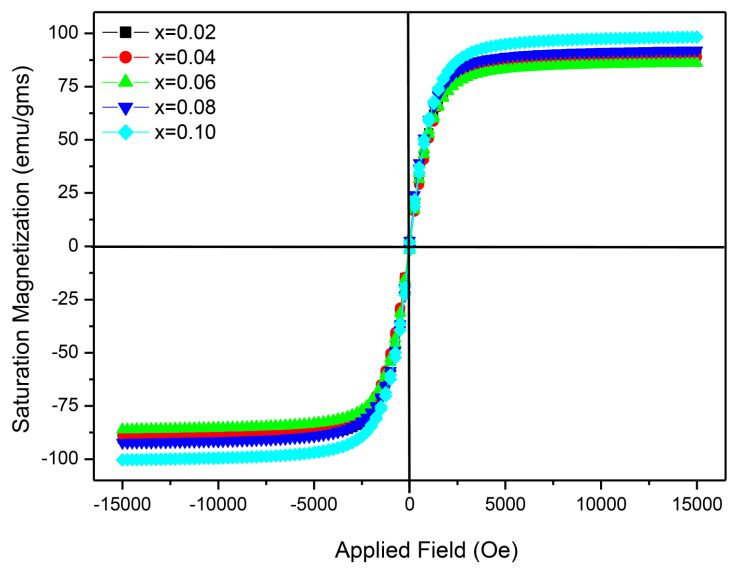

Fig. 8. Hysteresis loop presented for $\mathrm{Ni}_{0.5} \mathrm{Zn}_{0.3} \mathrm{Cu}_{0.2} \mathrm{Fe}_{2-x} \mathrm{Cr}_{x} \mathrm{O}_{4}(x=0.02,0.04,0.06$, 0.08 , and 0.10 ) ferrites.

The observed variation in saturation magnetization is explained on the basis of the Néel theory. According to the Néel theory the net magnetic moment is given by

$$
n_{\mathrm{B}}=M_{\mathrm{B}}-M_{\mathrm{A}},
$$

where $M_{\mathrm{B}}$ is the magnetic moment of B-sublattice, and $M_{\mathrm{A}}$ is the magnetic moment of A-sub lattice.

The magnetic moments of Ni, $\mathrm{Zn}, \mathrm{Cu}, \mathrm{Fe}$, and $\mathrm{Cr}$ are $2,0,1,5$, and $3 \mu_{\mathrm{B}}$, respectively. Considering cation distribution, the Néel magneton number are obtained with expression

$$
n_{B}=\frac{\text { molecular weight } \times M_{s}}{5585},
$$

where $n_{\mathrm{B}}$ is the magneton number of the samples, $M_{s}$ is the saturation magnetization of the samples. The values of coercivity are confirming the nanocrystalline nature of the synthesized ferrites. Further, it can be observed that with the increase in chromium concentration, the coercivity decreases. The coercivity values can be attributed to the substitution of nonmagnetic chromium ions in nickel ferrites. In general, the coercivity of ferrites depends upon magnetocrystalline anisotropy constant, the average grain size, domain wall energy, and several other parameters. Decrease in magnetic coercivity suggests decrease in magnetic losses. Hysteresis loss is proportional to the coercivity of the material [33-35].

The decrease in crystallite size and increase in the canting angle gives evidence that saturation magnetization and other magnetic parameters decrease as a result of spin canting, due to decrease in particle size. The observed magnetic behaviour cannot be perfectly explained on the basis of the Néel theory. The Yafet-Kittel model (YK) can explain the magnetic behaviour of the present samples. Thus, the substitution of chromium in $\mathrm{Ni}-\mathrm{Zn}-\mathrm{Cu}$ ferrite leads to decrease in saturation magnetization, magneton number, coercivity, and remanence magnetization magnetic properties.

\subsection{Initial permeability $\left(\mu_{i}\right)$}

The compositional variation of initial permeability measurements has been carried out using the Wayne-Kerr network analyser at room temperature at $20 \mathrm{~Hz}$ to $120 \mathrm{MHz}$. The initial permeability of toroids is calculated by using

$$
\mu_{i}=\frac{L}{0.0046 N^{2} h \log \frac{d_{2}}{d_{1}}},
$$

where $L$ is inductance in $\mu \mathrm{H}, N$ is number of turns, $d_{1}$ is inner diameter in $\mathrm{cm}, d_{2}$ is outer diameter in $\mathrm{cm}, h$ is height of the core in $\mathrm{cm}$. The variation of initial permeability for all the synthesized ferrites is shown in Fig. 9. From the figure, we observe that the permeability slightly increases gradually with increase in concentration. The increased permeability is due to the combined effect of increased grain size, and increased densification. It is also concluded that the low frequency dispersion may be attributed to the domain wall movement. This is attributed to increase in grain size with increase in concentration. Increasing concentration may causes decreasing magnetic anisotropy, thereby reducing the internal stresses and crystal anisotropy, which may result in minimum hindrance required for movement of the domain walls. Therefore, initial permeability increases with increase in dopant concentration [36-41].

\subsection{ESR spectroscopy}

The ESR spectra of as synthesized ferrite materials are shown in Fig. 10. The spectra of these samples show a single broad signal with $g$-value approximately 2.0, indicating the presence of $\mathrm{Fe}^{3+}$, $\mathrm{Cu}^{2+}, \mathrm{Zn}^{2+}, \mathrm{Cr}^{3+}$, and $\mathrm{Ni}^{2+}$ ions with dominance of $\mathrm{Fe}^{3+}$ ions signal. The variation in ESR parameters, such as peak-to-peak line width $\left(\Delta H_{P P}\right), g$-value and spin concentration of paramagnetic centres present in these ferrites, is discussed in terms of the inter-particle magnetic dipole-dipole interactions

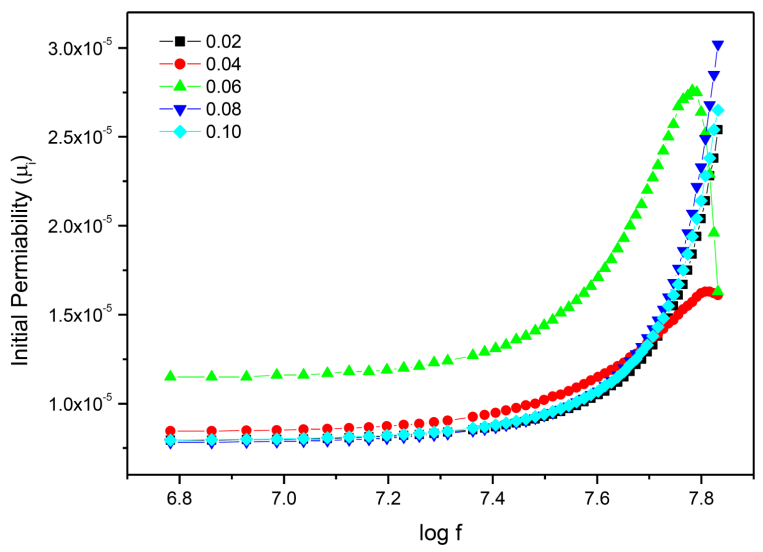

Fig. 9. Variation of initial permeability for $\mathrm{Ni}_{0.5} \mathrm{Zn}_{0.3} \mathrm{Cu}_{0.2} \mathrm{Fe}_{2-x} \mathrm{Cr}_{x} \mathrm{O}_{4}(x=0.02,0.04,0.06$, 0.08 , and 0.10$)$. 


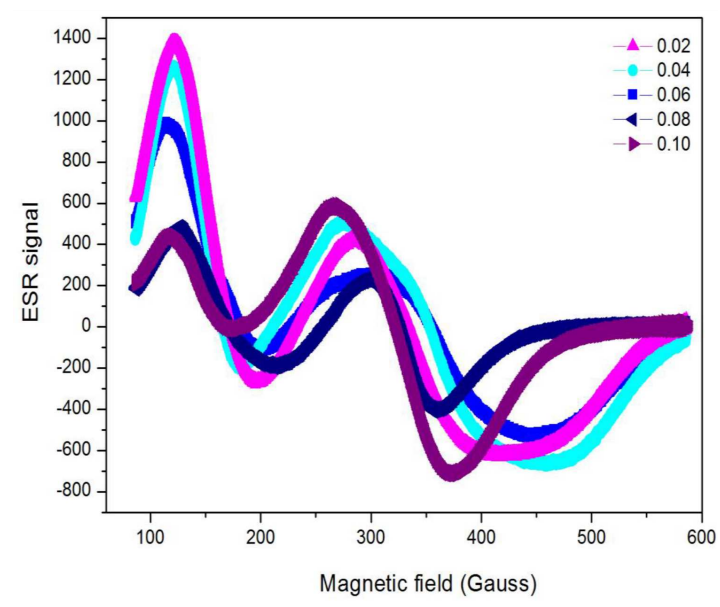

Fig. 10. ESR spectra results obtained for $\mathrm{Ni}_{0.5} \mathrm{Zn}_{0.3} \mathrm{Cu}_{0.2} \mathrm{Fe}_{2-x} \mathrm{Cr}_{x} \mathrm{O}_{4} \quad(x=0.02,0.04,0.06$, 0.08 , and 0.10 ).

and super-exchange interactions. The inter-particle super-exchange interaction between magnetic ions (through oxygen) can reduce the value of peak-topeak line width. The magnitude of this interaction is determined by the relative position of metallic and oxygen ions. The $g$-value increases on increasing chromium ions concentration in these ferrite samples, due to strengthening of super-exchange interaction via magnetic ordering within each sublattice of ferrite through rearrangement of cation between A-site and B-site. Resonance field value decreases with increase in the chromium content in these ferrite analogues with increase in intensity. The decrease in linewidth, i.e., narrowing of resonance derivative signal with respect to increase in chromium concentration has been attributed to the occupation of chromium ions at the octahedral B site. The presence of $\mathrm{Cr}^{3+}$ ions in the octahedral B-site causes a decrease in the magnetic moment of B-sublattice. This causes an overall decrease in total magnetic moment. This decrease in the magnetic moment of samples may be the reason for decrease in the linewidth of samples [42, 43].

\section{Conclusion}

The $\mathrm{Ni}_{0.5} \mathrm{Zn}_{0.3} \mathrm{Cu}_{0.2} \mathrm{Fe}_{2-x} \mathrm{Cr}_{x} \mathrm{O}_{4}(x=0.02,0.04$, $0.06,0.08$, and 0.10 ) ferrites are successfully synthesized through sol-gel method. The percentages of weight loss and gain have been obtained at different temperatures employing the thermal properties of synthesized ferrites. The X-ray diffraction confirms formation of single phase ferrite with no impurity. The SEM analysis indicates the uniform grain growth and less agglomeration. The FTIR spectrum exhibits two major absorption bands near $600 \mathrm{~cm}^{-1}$ and $400 \mathrm{~cm}^{-1}$ indicates the characteristic features of spinel ferrites. The initial permeability and dielectric loss tangent is found to increase at high frequency. Dielectric study shows the normal dielectric behaviour of all the samples and strong influence of frequency. The saturation magnetization $\left(M_{s}\right)$ and coercivity $\left(H_{c}\right)$ get decreased as chromium concentration increases. The present study thus reveals that sol-gel method is found to be one of the simplest effective chemical routes for preparing wide range of ferrites for diverse applications.

\section{Acknowledgments}

Authors are grateful to DST, Govt. of India, New Delhi for providing financial support through DSTPURSE Programme.

\section{References}

[1] E. Schloemann, J. Magn. Magn. Mater. 209, 15 (2000).

[2] S. Sharma, K. Verma, U. Chaubey, V. Singh, B.R. Mehta, Mater. Sci. Eng. B 167, 187 (2010).

[3] D.R. Patil, B.K. Chougule, Mater. Chem. Phys. 117, 35 (2009).

[4] R.V. Mangalaraja, S. Anantha Kumar, P. Manohar, F.D. Gnanam, J. Magn. Magn. Mater. 253, 56 (2002).

[5] L.Z. Li, X.X. Zhong, R. Wang, X.Q. Tu, J. Magn. Magn. Mater. 435, 58 (2017).

[6] F. Li, J.J. Liu, D.G. Evans, X. Duan, Chem. Mater. 16, 1597 (2004).

[7] A.V. Knyazev, I. Zakharchuk, E. Lähderanta, K.V. Baidakov, S.S. Knyazeva, I.V. Ladenkov, J. Magn. Magn. Mater. 435, 9 (2017).

[8] S.T. Alone, S.E. Shirsath, R.H. Kadam, K.M. Jadhav, J. Alloys Comp. 509, 5055 (2011).

[9] N. Rezlescu, L. Rezlescu, P.D. Popa, E. Rezlescu, J. Magn. Magn. Mater. 215, 194 (2000).

[10] S. Dey, S.K. Dey, B. Ghosh, P. Dasgupta, A. Poddar, V.R. Reddy, S. Kumar, J. Appl. Phys. 114, 093901 (2013).

[11] J.H. Jean, C.H. Lee, W.S. Kou, J. Am. Ceram. Soc. 82, 343 (1999).

[12] W.A. Bayoumy, M.A. Gabal, J. Alloys Comp. 506, 205 (2010).

[13] A.I. Borhan, V. Hulea, A.R. Iordan, M.N. Palamaru, Polyhedron 70, 110 (2014).

[14] H. Su, H. Zhang, X. Tang, Z. Zhong, Y. Jing, Mater. Sci. Eng. B 162, 22 (2009).

[15] W.C. Hsu, S.C. Chen, P.C. Kuo, C.T. Lie, W.S. Tsai, Mater. Sci. Eng. B 111, 142 (2004).

[16] M. Hashim, Alimuddin, S.E. Shirsath, S. Kumar, R. Kumar, A.S. Roy, J. Shah, R.K. Kotnal, J. Alloys Comp. 549, 348 (2013). 
[17] M. Hashim, Alimuddin, S. Kumar, S.E. Shirsath, R.K. Kotnalad, J. Shah, R. Kumar, Ceram. Inter. 39, 1807 (2013).

[18] M.Y. Lodhi, K. Mahmood, A. Mahmood, H. Malik, M.F. Warsi, I. Shakir, M. Asghar, M.A. Khan, Curr. Appl. Phys. 14, 716 (2014).

[19] P.B. Belavi, G.N. Chavan, L.R. Naik, R. Somashekar, R.K. Kotnala, Mater. Chem. Phys. 132, 138 (2012).

[20] R.D. Waldron, Phys. Rev. 99, 1727 (1955).

[21] R. Ali, A. Mahmood, M.A. Khan, A.H. Chughtai, M. Shahid, I. Shakir, M.F. Warsi, J. Alloys Comp. 584, 363 (2014).

[22] P. Priyadharsini, A. Pradeep, P.S. Rao, G. Chandrasekaran, Mater. Chem. Phys. 116, 207 (2009).

[23] S. Singhal, K. Chandra, J. Solid State Chem. 180, 296 (2007).

[24] M.N. Akhtar, M.A. Khan, M. Ahmad, M.S. Nazir, M. Imran, A. Ali, A. Sattar, G. Murtaza, J. Magn. Magn. Mater. 421, 260 (2017).

[25] X. Wu, W. Wu, L. Qin, K. Wang, S. Ou, K. Zhou, Y. Fan, J. Magn. Magn. Mater. 379, 232 (2015).

[26] C.G. Koops, Phys. Rev. 83, 121 (1951).

[27] N. Rezlescu, E. Rezlescu, Phys. Status Solidi A 23, 575 (1974).

[28] A.S. Fawzi, A.D. Sheikh, V.L. Mathe, J. Alloys Comp. 502, 231 (2010).

[29] R. Peelamedu, C. Grimes, D. Agrawal, R. Roy, P. Yadoji, J. Mater. Res. 18, 2292 (2003).

[30] Y. Koseoglu, Ceram. Int. 39, 4221 (2013).

[31] D. Ravinder, K. Vijayakumar, Bull. Mater. Sci. 24, 505 (2001).
[32] T.J. Shinde, A.B. Gadkari, P.N. Vasambekar, Mater. Chem. Phys. 111, 87 (2008).

[33] S.S. Ata-Allah, M.K. Fayek, H.S. Refai, H.F. Mostafa, J. Solid State Chem. 149, 434 (2000).

[34] A.B. Gadkari, T.J. Shinde, P.N. Vasambekar, J. Magn. Magn. Mater. 322, 3823 (2010).

[35] M. Gabal, Y.A. Angari, Mater. Chem. Phys. 118, 153 (2009).

[36] P.S. Aghav, V.N. Dhage, M.L. Mane, D.R. Shengule, R.G. Dorik, K.M. Jadhav, Physica B Condens. Matter 406, 4350 (2011).

[37] Z.H. Khan, M.M. Rehman, S.S. Sikder, M.A. Hakim, D.K. Saha, J. Alloys Comp. 548, 208 (2013).

[38] J.S. Ghodaken, T.J. Shinde, R.P. Patil, S.B. Patil, S.S. Suryavanshi, J. Magn. Magn. Mater. 378, 436 (2015).

[39] A.P. Guimaraes, I.S. Oliveira, Magnetism and Magnetic Resonance in Solids, 2nd ed., Wiley, 1998.

[40] K.O. Low, F.R. Sale, J. Magn. Magn. Mater. 246, 30 (2002).

[41] M. Kaiser, J. Phys. Chem. Solids 71, 1451 (2010).

[42] S.A.V. Prasad, P.N. Ramesh, M. Deepty, G. Prasad, K. Srinivasa Rao, Ch. Srinivas, K. Vijaya Babu, S.S. Meena, E. Ranjit Kumar, D.L. Sastry, Ceram. Int. 44, 10517 (2018).

[43] K.V. Babu, B. Sailaja, K. Jalaiah, P.T. Shibeshi, M. Ravi, Physica B Condens. Matter 534, 83 (2018). 